\title{
Backward rod extrusion of bimetallic aluminum-copper alloys at room temperature
}

Cite as: AIP Conference Proceedings 2113, 030001 (2019); https://doi.org/10.1063/1.5112529

Published Online: 02 July 2019

V. Sanabria, S. Gall, F. Gensch, R. Nitschke, and S. Mueller

\section{ARTICLES YOU MAY BE INTERESTED IN}

Numerical investigations on the cold welding of aluminum and steel using forward extrusion AIP Conference Proceedings 2113, 030003 (2019); https://doi.org/10.1063/1.5112531

Extrusion of magnesium alloy hollow profiles with axial variable wall thickness AIP Conference Proceedings 2113, 030002 (2019); https://doi.org/10.1063/1.5112530

256 shades of gray: Application of image processing to evaluate the effect of sample geometry and constant shear strain rates in the picture-frame test

AIP Conference Proceedings 2113, 020001 (2019); https://doi.org/10.1063/1.5112506

\section{Lock-in Amplifiers up to $600 \mathrm{MHz}$

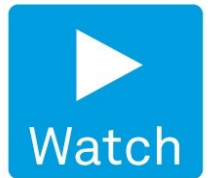

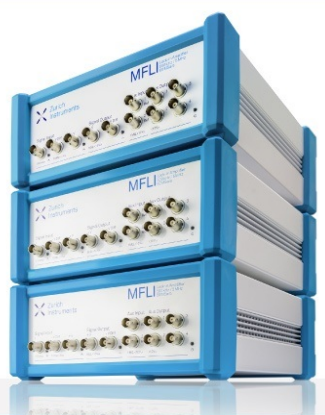




\title{
Backward Rod Extrusion of Bimetallic Aluminum-Copper Alloys at Room Temperature
}

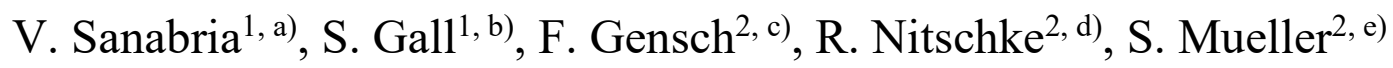 \\ ${ }^{1}$ INGWERK GmbH. Gustav-Meyer-Allee 25, Gebäude 17a, Treppe 5, 13355 Berlin. \\ ${ }^{2}$ Extrusion Research and Development Center ERDC, TU Berlin. Forschungszentrum Strangpressen, Sekr. TIB 4/1- \\ 2. Gustav-Meyer-Allee 25, 13355 Berlin \\ ${ }^{a}$ Corresponding author: vidal.sanabria@ingwerk.com \\ b)sven.gall@ingwerk.com \\ c)felix.gensch@strangpressen.berlin \\ d)rene.nitschke@strangpressen.berlin \\ e)soeren.mueller@strangpressen.berlin
}

\begin{abstract}
The backward rod extrusion of bimetallic aluminum-copper alloys at room temperature was investigated. The aluminum alloy EN AW-1080A and the copper alloy $\mathrm{Cu}$-ETP were selected to prepare the core and sleeve of the billet respectively. The copper cross section was equivalent to $30 \%$ of the billet. Moreover, the billet was extruded applying a conic die angle of $90^{\circ}$ and an extrusion ratio of 14:1. Experimental results demonstrated that the combination of grounding marks on the die surface and the application of graphite foil reduced drastically the friction between copper and the conic die. Thus, a uniform material flow of aluminum and copper through the bearing channel was observed during the steady state of the extrusion process. However multiple fractures of the copper sleeve occurred at the end of the process. The extrusion process was numerically simulated applying the FEM-based software Deform $2 \mathrm{D}$ in order to estimate the state variables and material flow. The die and punch temperature evolution, as well as the die extrusion force were recorded during the whole process to facilitate the validation of the numerical analysis.
\end{abstract}

\section{INTRODUCTION}

The excellent electrical and thermal conductivity of cooper alloys make them ideal materials for conductors. However, the high density, low availability and instable prices have motivated their substitution in industrial applications. Due to the rich availability, low price and density, as well as good electric conductivity of aluminum alloys, they have been used as a substitute material for copper for more than fifty years. Nevertheless, a hard and brittle aluminum oxide appears on the surface increasing thus its electrical contact resistance. Copper-clad aluminum compound is an efficient alternative for this challenge and gives a good compromise between conductivity and weight. Thus, the compound weight can be reduced in $50 \%$ for an equivalent conductivity comparing to copper and additionally a better contact can be achieved. Copper-clad aluminum profiles are usually manufactured by means of hydrostatic extrusion (Fig. 1(a)).

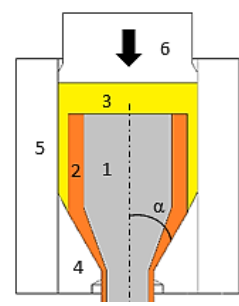

(a)

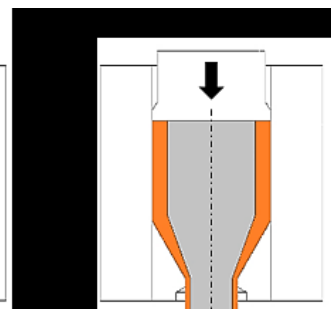

(b)

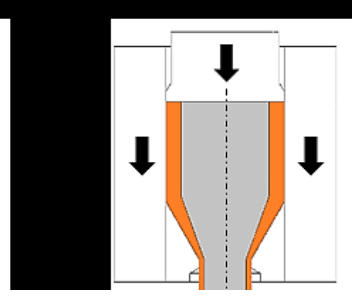

(c)

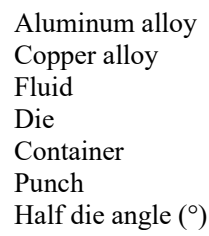

FIGURE 1. Schematic representation of (a) hydrostatic, (b) direct and (c) indirect extrusion. 
During this process a fluid transmits the driving force from punch to workpiece, which is forced to flow plastically through the die. Moreover, the fluid acts also as lubricant reducing significantly the friction between sleeve (copper) and die and therefore a more uniform material flow is possible. On the other hand, the complicated billet preparation process, sealing issue as well as the long cycle times makes the hydrostatic extrusion a complex and expensive process.

In the forward and backward extrusion the billet is in contact with the tools and important frictional and thermal effects are generated. Due to the high friction between the sleeve and the container/die in the forward extrusion (Fig. 1(b)) and sleeve and die in the backward extrusion (Fig. 1(c)), the sleeve flows slower than the core. This phenomena generates non-uniform material flow and undesired fractures of the sleeve or core material. Experimental investigations have demonstrated that copper clad aluminum profiles can be also manufactured by means of forward and backward extrusion under determined billet configuration and process parameters. In general, authors agree that a conic die, low extrusion ratio and a well lubrication between die and sleeve facilitate a sound material flow and minimize the fractures $[1,2,3]$. A small conic die angle as well as a low extrusion ratio reduce the normal contact force between the sleeve and die. This geometrical condition coupled with an appropriate lubrication reduces the friction on the die surface and therefore generates a more uniform material flow [4]. Kang and Kwon successfully extruded copper clad aluminum profiles with a maximal extrusion ratio of 7:1 [1,2]. They extruded short profiles without fracture using a conic die angle of $60^{\circ}$ which was lubricated with carbon oil. Additionally, the core and sleeve were heated to $300{ }^{\circ} \mathrm{C}$ and $350{ }^{\circ} \mathrm{C}$ respectively before extruding.

A more intimate initial interface bonding between core and sleeve also improve the material flow and the final mechanical and thermal interface properties. Different billet preparation methods such as pressurization joining by cold compression [1], low pressure casting [3] and explosive cladding [5] of the aluminum rod in the copper pipe are applied. However, these complex preparation methods applied in conventional forward or backward extrusion make the processes more expensive and reduces their competitiveness in relation to hydrostatic extrusion.

The initial billet temperature plays also an important role in the appropriate material flow during copper clad aluminum extrusion. Experimental and numerical investigations showed a more uniform material flow at lower temperatures [2,3]. At higher temperatures the flow stress difference between the aluminum and copper increases. Kwon and coworkers suggested that the flow stress of copper was 4 to 7 times higher than that of pure aluminum at $350{ }^{\circ} \mathrm{C}$, but 7 to 13 times higher at $470{ }^{\circ} \mathrm{C}$ [2]. Therefore, a longer aluminum nose crop is usually observed when a higher initial billet temperature is applied.

In this work industrial scaled backward extrusion of copper clad aluminum profiles was investigated. For that purpose, a simple billet preparation was carried out. Additionally, a relative high extrusion ratio (14:1) and a moderate conic die angle $\left(90^{\circ}\right)$ was applied. Moreover, the billet and the tools were not heated and the deformation process was performed initially at room temperature.

\section{EXPERIMENTAL PROCEDURE}

A backward rod extrusion of bimetallic aluminum-copper alloys was carried out at the ERDC of the TU Berlin. Since the $8 \mathrm{MN}$ press is equipped with load cells, the extrusion force was recorded during the whole process. The aluminum alloy EN AW-1080A and the copper alloy Cu-ETP were selected to prepare the core and sleeve of the billet respectively (Fig. 2(a)). The copper alloy was soft annealed at $600{ }^{\circ} \mathrm{C}$ for 3 hours in order to reduce the flow stress. The core was intentionally shorter than the sleeve to reduce the nose crop [6]. Moreover, the core and sleeve surfaces were cleaned with ethanol before assembly. A clearance fit between them was applied to facilitate the billet preparation. Furthermore, the external diameter of the core and sleeve were $77.4 \mathrm{~mm}$ and $93 \mathrm{~mm}$, respectively. Thus, the copper cross section was equivalent to $30 \%$ of the billet section.

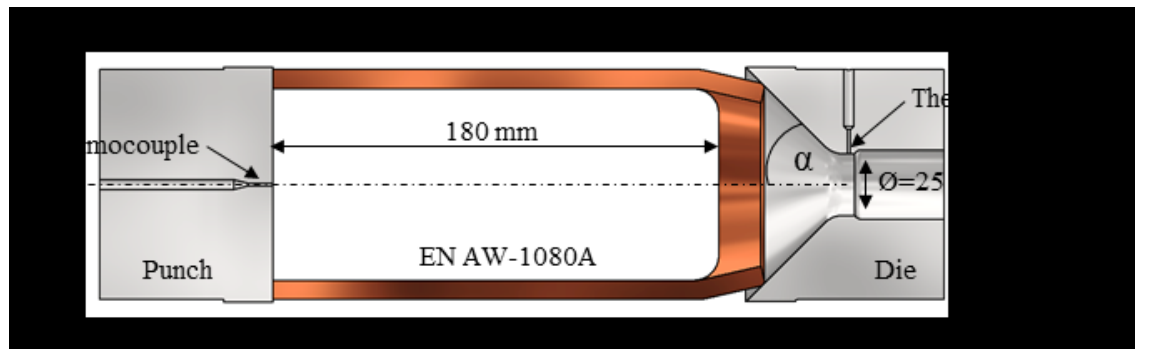

(a)

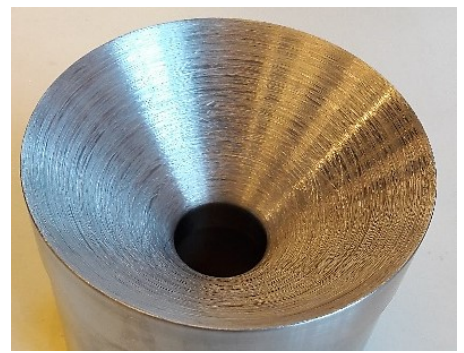

(b)

FIGURE 2. Extrusion assembly. (a) Schematic representation of block assembly and (b) extrusion die. 
After core and sleeve were assembled, the billet was completely covered with the graphite paper Grafoil GTB ( $250 \mu \mathrm{m}$ thickness) which is usually used to reduce the friction between workpiece and tools during hot compression test [7]. Subsequently, the billet was introduced into a container $(\varnothing=95 \mathrm{~mm})$ at room temperature and indirectly extruded against a conic die $\left(2 \alpha=90^{\circ}\right)$ with a ram speed of $5 \mathrm{~mm} / \mathrm{s}$. The initial temperature of billet, container, die and punch was $25^{\circ} \mathrm{C}$ approximately. It is important to notice that the conic die face was not polished but ground with SiCpaper grid 80 (Fig. 2(b)). In addition, the die-face was covered with a graphite-based lubricant which was burned in the surface at $400^{\circ} \mathrm{C}$. Thermocouples were placed in the die bearing channel and in the punch head in order to register the temperature evolution (Fig. 2(a)).

\section{RESULTS AND DISCUSSION}

The extrusion of the Copper clad aluminum profile at room temperature could be carried out applying a conic die and an extrusion ratio of 14:1. Figure 3 describes the most relevant geometric characteristics of the profile. The extruded rod had a full aluminum head (zone A) with a length of $110 \mathrm{~mm}$, followed by $1490 \mathrm{~mm}$ of uniform aluminumcopper bimetallic compound (zone B). In the last part of the rod (zone C) multiple fractures of the copper sleeve occurred, and actually this section was longer $(890 \mathrm{~mm}$ ) than expected. The nose crop (Fig. 3, zone A) could not be avoided even using a longer sleeve, mainly due to the greater flow resistance of the copper. This effect was also observed in similar investigations $[3,5,6]$. Additionally, the sleeve fracture has been also reported and it represents one of the big challenges in the copper-clad aluminum extrusion. In Ref (2) it was suggested that the copper fracture occurs due to the large difference of flow stress between core and sleeve materials.

In order to investigate the thermo-mechanical response of EN AW-1080A and soft annealed Cu-ETP hot compression tests were carried out. Thus, small specimens (diameter $=10 \mathrm{~mm}$, height $=15 \mathrm{~mm}$ ) were tested in the Gleeble System 3800 at different temperatures $\left(20-300{ }^{\circ} \mathrm{C}\right)$ and strain rates $(0.01-101 / \mathrm{s})$. Results of the tests are depicted in Fig. 4. Figures 4(a) and 4(b) show strain-stress curves of Cu-ETP and EN AW-1080A respectively. As expected, the flow stress increases with the strain and strain rate but it is reduced at higher temperatures. However, more relevant than the magnitude of the flow stress is the relative value between flow stress of aluminum and copper. Hot compression tests demonstrated that when the alloy EN AW-1080A is heated from $20^{\circ} \mathrm{C}$ to $300{ }^{\circ} \mathrm{C}$ its flow stress is reduced more than $50 \%$, whereas the Cu-ETP alloy decreased $30 \%$ under the same conditions (Fig. 4(c)). In other words, the flow stress ratio $\sigma_{\mathrm{Cu}} / \sigma_{\mathrm{Al}}$ increases from 3.3 to 5.1, considering a strain rate of $101 / \mathrm{s}$ and strain 1 . It confirms the observations made in [2].

The extrusion process was numerically analyzed applying the FEM-based software Deform 2D in order to investigate more about the material flow and state variables. Constitutive models $\sigma=f(\varepsilon, \dot{\varepsilon}, \mathrm{T})$ of the aluminum alloy EN AW-1080A and the copper alloy Cu-ETP were set based on the experimental results of the hot compression tests. Additionally, the flow stress curves were extrapolated from a strain 1 to 5 using exponential equations fitted to the experimental results. The Tresca friction model was selected to simulate the friction. Thus, a friction factor $m=1$ was set between core and sleeve, and $m=0.17$ between workpieces (core and sleeve) and tools. Friction factors of $m=0.2$ and $m=0.25$ have been reported in extrusion trials where lubrication with carbon oil has been applied $[1,3]$. The heat transfer coefficient of $30 \mathrm{~kW} / \mathrm{m}^{2}$ was set between all objects [1]. Additionally, the die, container and punch were simulated as rigid objects (no elastic deformation), but internal heat transfer was allowed.

Figure 5(a) depicts the experimental and simulated extrusion force (die force) during the whole stroke $(175 \mathrm{~mm})$. Moreover, the simulated material flow of core and sleeve is shown in Fig. 5(b). Three main points of the curve are emphasized. Thus, point 1 indicates the instant when the bearing channel is filled with aluminum to form the nose crop (Fig. 3). Moreover, the point 2 shows the maximal extrusion force, which is generated when the copper sleeve begins to flow though the bearing channel.

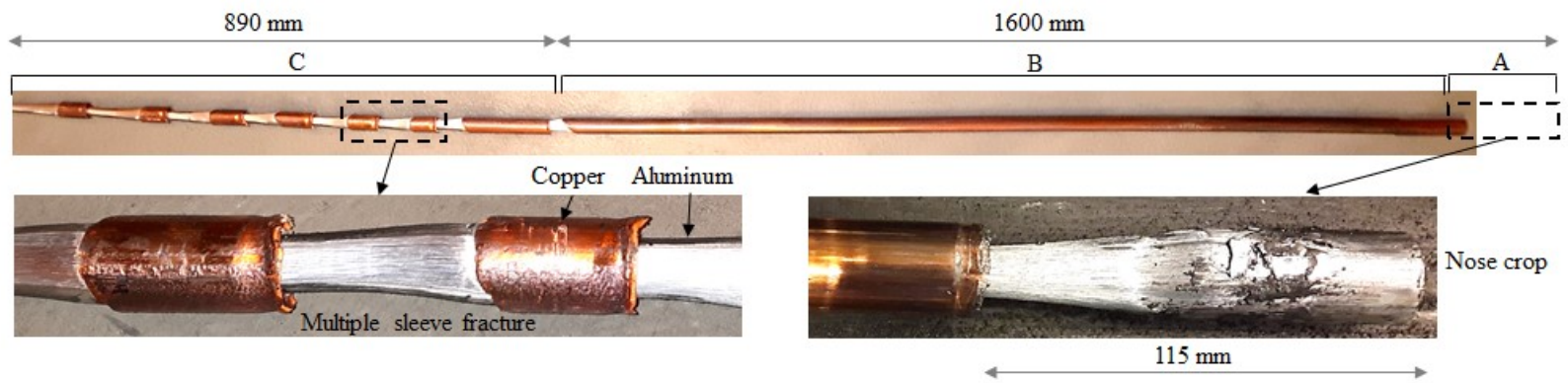

FIGURE 3. Description of the extrudate. 


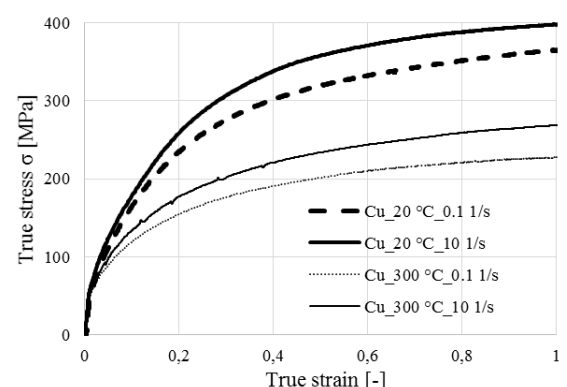

(a)

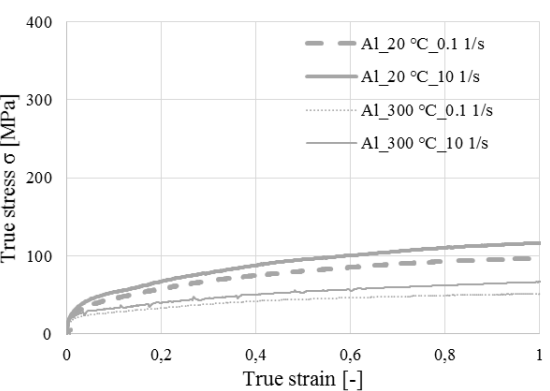

(b)

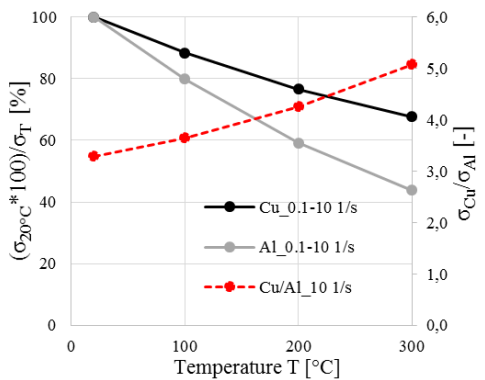

(c)

FIGURE 4. Thermo-mechanical behavior of copper and aluminum alloys. (a) Strain-stress curves of homogenized Cu-ETP, (b) strain-stress curves of EN AW-1080A and (c) variation of the flow stress ratio at higher temperatures.

Additionally, the point 3 illustrates the beginning of multiple sleeve fractures also depicted as zone C (Fig. 3). Finally, the simulated die force and the sequence of the material flow are depicted in Fig. 5(a) and 5(b), respectively. The numerical analysis could estimate the magnitude of the die force in the point 1 and in the steady state (Zone B) with an acceptable difference of $5 \%$. Moreover, fracture could not be predicted, since fracture behavior was not simulated. However the die force in the point 2 was around $25 \%$ underestimated. The reason for this discrepancy could be related to an inappropriate simulation of the friction between copper and die (step 397). During the simulation a constant friction factor $m=0.17$ was set between sleeve and die. It means that the normal force between both metals and its influence on the friction behavior was not considered. In the real case, sleeve and die surface could shortly stick under very high normal pressure (such as the point 2) particularly using the grounded die face (even using graphite paper as lubrication) then subsequently start to slip. This transient friction mechanism increases significantly the local shear stress and therefore the total die force. As the temperature increases in the primary deformation zone and the copper sleeve becomes thinner the required extrusion force as well as the normal force drop. Under this contact phenomena the friction behavior changes and it can be only partially reproduced applying a constant friction factor $m$.

Figure 6(a) depits the experimental and simulated geometry of the nose crop. It can be observed that the length of the aluminum head was properly predicted with only $5 \%$ of deviation. Nevertheless, the length of the necking zone was about $30 \%$ overestimated. The prediction of the aluminum nose geometry is strongly related to the friction modelling between worpieces and die during the first $37 \mathrm{~mm}$ of stroke (Fig. 5(b)). In this part of the simulation, the conic die is filled by the core and sleeve materials, which are forced to flow plastically through the bearing channel.

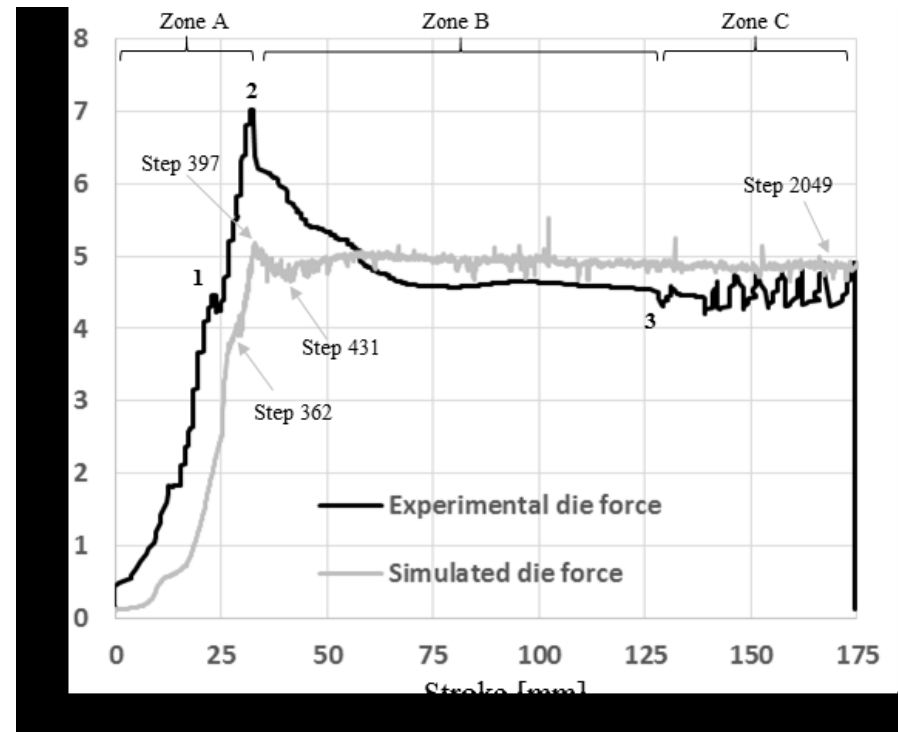

(a)

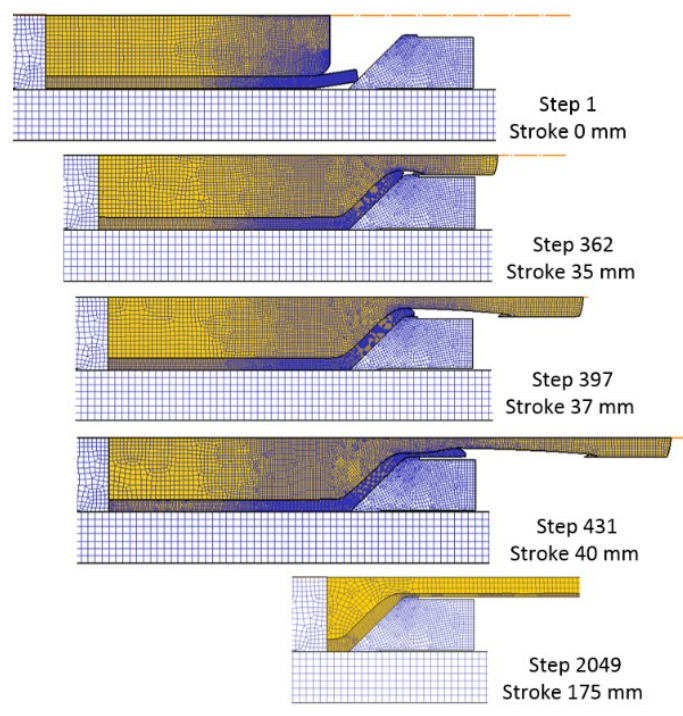

(b)

FIGURE 5. Experimental and numerical results. (a) Comparison of experimental and simulated die force and (b) simulated material flow. 


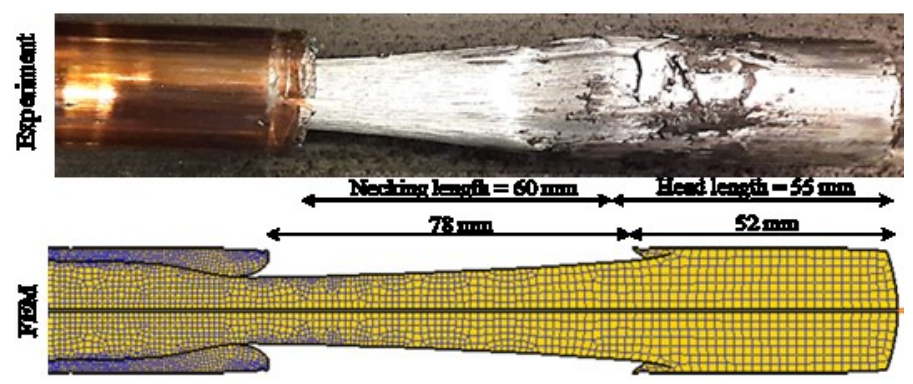

(a)

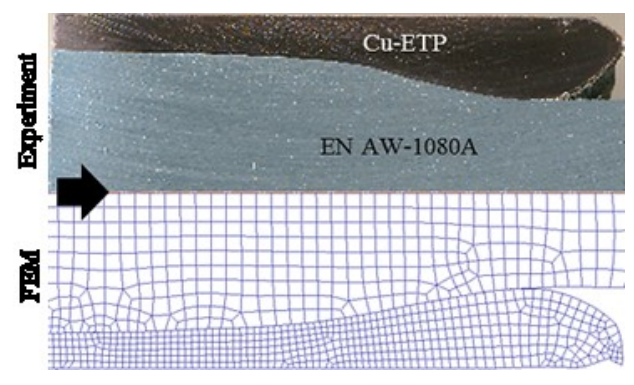

(b)

FIGURE 6. Experimental and numerical comparison of the initial material flow. (a) Nose crop and (b) initiation of the bimetallic extrude (stroke $40 \mathrm{~mm}$, step 431). Extrusion direction from left to right.

In general, a high friction factor between die and sleeve delays the copper flow and generates a longer aluminum head. Since the head length was correctly predicted, a good friction simulation until the stroke $35 \mathrm{~mm}$ (step 362) can be assumed (Fig. 5(b)). On the other hand, the inaccurate prediction of the necking length suggests that the same friction relationship used until the step 362 are inapropiate for the steps 363-397. Friction is influenced by temperature, pressure, speed, etc and therefore more accurate results can be only obtained applying a more sensitive friction model $\mathrm{m}=f(\mathrm{~T}, \mathrm{P}, \mathrm{v})[7,8]$. In addition, the longer necking legth and lower extrusion force (point 2 in Fig. 5(a)) obtained with the numerical simulation can be also explained due to an insufficient metal bonding (low friction) between core and sleeve. A higher metal bonding between the $\mathrm{Cu}-\mathrm{ETP}$ and EN AW-1080A alloys could take place at the bearing channel generating a more severe deformation and therefore a higher extrusion force at the beginning of the extrusion process. Moreover, this stronger metal bonding could reduce the core speed and thus the length of the aluminium head. Fig. 6(b) compares the experimental and simulated geometries at the front end of the bimetallic rod.

Initially, a thermocouple was placed inside the bearing channel to measure the profile temperature (Fig. 2(a)). However, this thermocouple was pushed backwards into the bore and covered by remaining graphite paper during the extrusion. Thus, the measured tempertaure corresponds to the bearing land and not the profile surface. Figure 7(a) compares the experimental and simulated temperatures of the die land and stem surface. The simulated die temperature was taken at a location $0.3 \mathrm{~mm}$ behind the bearing land. Experimental and simulated temperatures are very similar up to point 3 (stroke $130 \mathrm{~mm}$ ), where fracture took place. Once the die force, material flow and temperature evolution were validated until stroke $130 \mathrm{~mm}$, simulation results can be used to analyse the occurrence of the fracture.

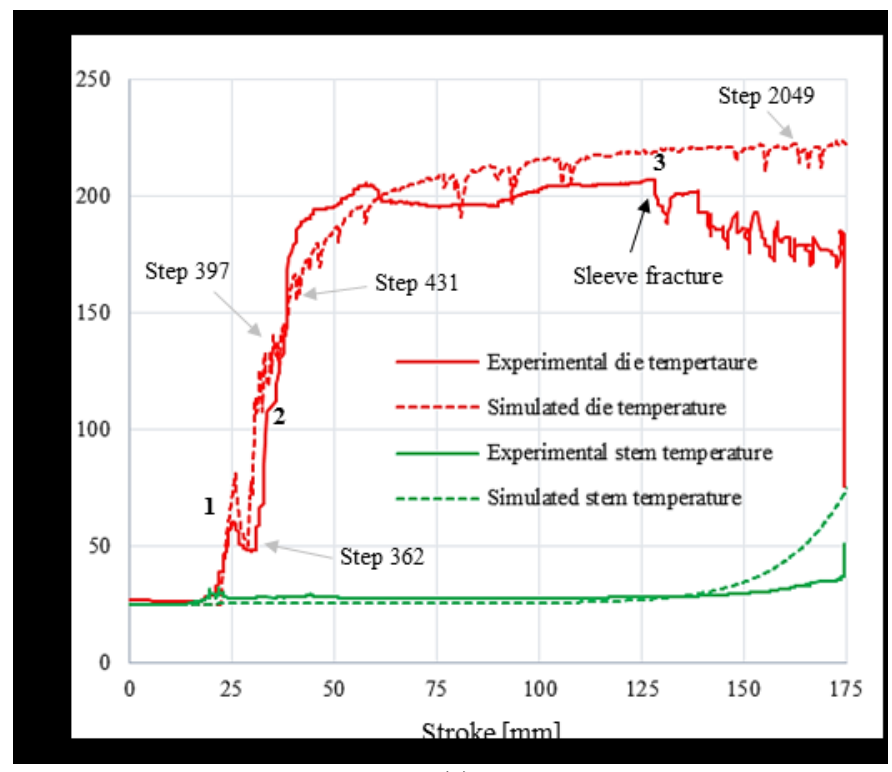

(a)

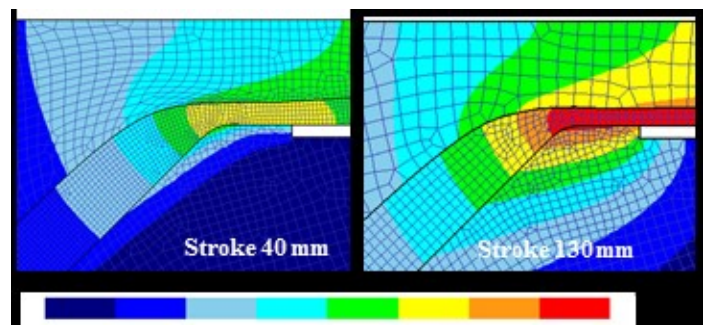

(b)

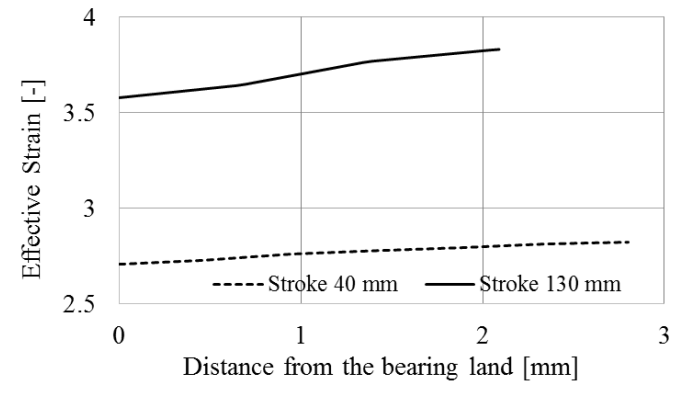

(c)

FIGURE 7. Experimental and simulated results. (a) Experimental and estimated temperature, (b) simulated temperature distribution in primary extrusion zone and (c) simulated effective strain in the bearing channel across the copper alloy. 
The exact origin of the sleeve fracture in the zone C (Fig. 3) is still object of investigation, however it can be related to its temperature evolution, strain and friction inside the bearing channel. According to the simulation results, the copper sleeve placed inside the bearing channel is the hottest area in the primary deformation zone. It reached around $180^{\circ} \mathrm{C}$ at the stroke $40 \mathrm{~mm}$ (step 397) and then $250^{\circ} \mathrm{C}$ at the fracture instant (Fig. 7(b)). A higher temperature of the sleeve can be related to the fracture initiation, however a higher fracture elongation is allowed at higher temperatures [9]. For that reason, a temperature increase during the extrusion process may not cause this failure. On the other hand, a temperature increase generates a higher flow stress ratio $\sigma_{\mathrm{Cu}} / \sigma_{\mathrm{Al}}$ as shown in Fig. 4(c), what may initiate fracture [2]. Moreover, ductile fracture investigations of Cu-ETP revealed the significant influence of the strain on the formation and nucleation of voids [10]. Thus, the fracture will be initiated at a critical plastic strain. Theoretically, during the backward extrusion the workpiece experiences an average strain in the primary deformation zone, which remains constant after reaching the steady state stage [11]. Numerical simulation made in the present investigation revealed that strain changed due to the setting up or compression of the billet in the die at the beginning of the extrusion, as well as the thickness variation of the copper sleeve. Thus, the sleeve thickness inside the bearing channel was for example $5.7 \mathrm{~mm}$ and $2.1 \mathrm{~mm}$ at the stroke $40 \mathrm{~mm}$ and $130 \mathrm{~mm}$, respectively. Figure 7® shows the effective strain across the copper sleeve and its thickness. The numerical results predicted a maximal effective strain of 2.7 at the strokes $40 \mathrm{~mm}$ and 3.8 at the fracture instance (stroke $130 \mathrm{~mm}$ ). Another possible cause for the fracture occurrence is the strain may increase due to reduction of lubrication between sleeve and die. In the simulation a constant friction factor was applied, however the lubrication capacity can be progressively reduced during the extrusion stroke.

\section{SUMMARY}

An industrial scale backward extrusion of copper clad aluminum profile was investigated at room temperature. Aluminum alloy EN AW-1080A and the copper alloy Cu-ETP were applied in the core and sleeve of the billet respectively. Almost $1500 \mathrm{~mm}$ of bimetallic profile was successfully extruded, mainly due to the friction reduction between the copper sleeve and the conic die face. This was possible since the billet was completely covered with the graphite paper Grafoil GTB (250 $\mu \mathrm{m}$ thickness). Additionally, the conic die face was with a high surface roughness by grinding with $\mathrm{SiC}$-paper grid 80 and subsequently covered with a graphite-based lubricant, which was burned onto the surface at $400{ }^{\circ} \mathrm{C}$.

Fracture of the copper sleeve was observed at $75 \%$ of the stem stroke $(130 \mathrm{~mm})$. The exact origin of this failure is still under investigation. Moreover, the increase of the flow stress ratio $\sigma_{\mathrm{Cu}} / \sigma_{\mathrm{Al}}$ at higher temperatures, as well as the progressive increase of the plastic strain seem to be the main cause for the fracture occurrence.

The investigation shows that a cold aluminum core and hot copper sleeve would reduce the flow stress ratio between the two applied alloys and could contribute to a more uniform material flow.

\section{ACKNOWLEDGEMENTS}

The authors are grateful for the financial support of the German Research Foundation (DFG) under the contract no. MU2963/14-1.

\section{REFERENCES}

1. C. Kang and H. Kwon, International Journal of Mechanical Sciences 44, 247-267 (2002).

2. J. Luo, Y. Xu and S. Zhao, Applied Mechanics and Materials 16-19, 441-444 (2009).

3. H. Kwon, T. Jung, S. Lim and M. Kim, Materials Science Forum 449-452, 317-320 (2004).

4. B. Avitzur, R. Wu, S. Talbert and Y. Chou, Journal of Engineering for Industry 104, 293-304 (1982).

5. P. Kazanowski, M. Epler and W. Misiolek, Materials Science and Engineering A 369, 170-180 (2004).

6. S. Berski et al. Journal of Materials Processing Technology 177, 582-586 (2006).

7. V. Sanabria, S. Mueller and W. Reimers, Materials Today: Proceedings 2, 4820-4828 (2015).

8. P. Hora et al., Key Engineering Materials 585, 41-48 (2014).

9. M. Bauser, G. Sauer and K. Siegert, Strangpressen (Aluminium-Verlag, Duesseldorf, 2001), pp. 265-266.

10. M. Mirza, D. Barton, P. Church and J. Sturges, "Ductil fractrure of pure copper: an experimental and numerically study. Journal de Physique IV Colloque, 1997, 07 (C3), pp. C3-891-C3896.

11. K. Mueller et al, Fundamental of Extrusion Technology, (Giesel Verlag GmbH, Isernhagen, 2004), pp.24-26. 